\title{
BALL-MILLED HYDROGEN STORAGE IN Mg-Cu - BASED ALLOYS MODIFIED BY KCl: DISTRIBUTION OF COMPONENTS
}

\author{
1,2Jiri CERMAK, 'Lubomir KRAL, ${ }^{1,3}$ Pavla ROUPCOVA \\ 1 IPM AS CR, Brno, Czech Republic, EU, cermak@ipm.cz, Ikral@ipm.cz, roupcova@ipm.cz, \\ ${ }^{2}$ CEITEC-IPM, Brno, Czech Republic, EU, cermak@ipm.cz \\ ${ }^{3}$ CEITEC-BUT, Brno, Czech Republic, EU, pavla.roupcova@ceitec.vutbr.cz
}

https://doi.org/10.37904/metal.2021.4213

\begin{abstract}
Magnesium and its alloys is a class of materials, which is still one of the most prospective hydrogen storage (HS) compositions. This is due before all to their high hydrogen sorption capacity and low cost. However, pure Mg must be alloyed with other elements to suppress the tendency to Mg oxidation and to improve the otherwise lazy ab/desorption kinetics and to decrease the operation temperature. Also some modifiers, as e.g., hall elements and alkali metals, are known to enhance the HS characteristics. It is known that sorption performance can be further substantially enhanced by nanosizing. This paper is devoted to study of distribution of components in $\mathrm{Mg}-\mathrm{xCu}$ alloys ( $\mathrm{x}=9.94-21.56 \mathrm{wt} \%$ ) prepared by high-energy ball-milling (BM). Elements $\mathrm{K}$ and $\mathrm{Cl}$ - as modifiers - were introduced by $\mathrm{BM}$ of the $\mathrm{Mg}-\mathrm{Cu}$ base with addition of $\mathrm{KCl}$. It was found that $\mathrm{KCl}$ decomposed partly into elements, which entered grains of milled blend. Chlorine anions entered preferentially the Mg-rich regions.
\end{abstract}

Keywords: Ball-milling, magnesium, copper, hydrogen storage

\section{INTRODUCTION}

Nowadays, all human activities bring growing demands on storage of energy and its easy transportation. It is known for a long time that one of safe and clean energy carrier may be hydrogen [1]. Contrary to many unsolved technologic problems in the complete chain of practical hydrogen energy utilization, hydrogen is still considered for a prospective energy carrier. It is due to the important fact that hydrogen-based energetic avoids generation of greenhouse gases. Among the most challenging tasks is suitable hydrogen storage, which would increase the volumetric energy density. It should be remarked at this place that hydrogen compression and liquefaction is neither safe nor sufficiently effective. Hydrogen storage in the form of solid hydrides is generally considered much more prospective [2].

Under various materials, magnesium based hydrides still belong to the most promising storage ones [3]. There are, however, problems that impede the introduction of pure $\mathrm{Mg}$ as a storage material into the practice. The most serious ones are bias to $\mathrm{Mg}$ oxidation, high operation temperature of magnesium charging/discharging and lazy desorption kinetics. They originate mostly in high thermodynamic stability of the magnesium hydride $\mathrm{MgH}_{2}$. On the other hand, abundance of $\mathrm{Mg}$ on the Earth, its low cost and high hydrogen storage capacity (theoretically $7.6 \mathrm{wt} \%$ ), are advantageous features that overbalance the drawbacks.

Many attempts were undertaken to influence magnesium hydride formation enthalpy with the aim to reduce its stability and to facilitate the hydrogen desorption. Nanosizing, modifying with additives and catalysis of the sorption process are the main ways how to achieve improving in storage performance of Mg-based alloys [4]. 
Copper is a transition metal that was - as an additive to $\mathrm{Mg}$ - frequently studied. A special attention focused to structure, nanosizing and sorption catalysis of $\mathrm{Mg}$ storage alloys with $\mathrm{Cu}$ was paid, e.g., in papers [5]. Catalytic role of $\mathrm{Cu}$ in hydrogen sorption in $\mathrm{Mg}$-Cu binary alloy system was investigated in papers [6].

Results on sorption behavior in the Mg-Cu system published up to now are still incomplete. Moreover, it was reported that small additions of halide elements, either in the crystalline form or in the dissociated form of separated ions show a significant catalytic effect upon hydrogen desorption [7]. This is why the system deserves more detailed study. As a first step, it is important to clear the modus of additive distribution. Therefore, the goal of the present paper is to investigate how the additive elements are distributed over the main phases in BM blend. As model elements, potassium and chlorine were chosen that showed beneficial effect upon the storage behavior in our recent study [8].

\section{EXPERIMENTAL}

Samples were prepared from pure $\mathrm{Mg}$ (purity $3 \mathrm{~N} 5)$ and $\mathrm{Cu}(6 \mathrm{~N})$ in the form of splinters. Crystalline $\mathrm{KCl}(3 \mathrm{~N})$ was introduced to each milling batch as an anti-sticking additive and also as a component that improves the hydrogen storage performance. It was reported [7] that halides, either in the crystalline form or in the dissociated form of separated ions show a significant catalytic effect upon hydrogen desorption.

Three experimental alloys were prepared by high energy BM in hydrogen atmosphere (under the pressure of about 1 bar) using Fritsch Pulverisette6 ball-mill. Details of sample preparation were described elsewhere [7].Chemical composition of samples is listed in Table 1.

Table 1 Chemical composition (wt\%)

\begin{tabular}{|c|c|c|c|}
\hline & \multicolumn{3}{|c|}{ composition of BM samples (wt\%) } \\
\hline element & 1 & 2 & 3 \\
\hline $\mathrm{Mg}$ & 56.47 & 51.27 & 39.5 \\
\hline $\mathrm{Cu}$ & 9.94 & 15.14 & 21.56 \\
\hline $\mathrm{KCl}$ & 33.59 & 33.59 & 38.94 \\
\hline
\end{tabular}

After the BM, the samples were thermally treated (activated) in order to approach the stable structure and composition. The treatment involved several sorption cycles at temperature $360^{\circ} \mathrm{C}$ consisting of hydrogen charging under pressure of 50 bars for about $3 \mathrm{~h}$ and total hydrogen discharging. All manipulations of the milled blend were done in the glove box in a protective Ar atmosphere.

Local chemical composition was done using SEM TESCAN LYRA3 equipped with X-max80 EDS in points and/or within small rectangular areas in chosen locations at surface of each sample. For the phase analysis XRD EMPYREAN device using CoKa was used.

\section{RESULTS AND DISCUSSION}

Experimental results were obtained for all three samples, but the procedure and sample characterization is illustrated below for the sample 2 only, because chemical composition of the sample 2 is approximately in the centre of the concentration interval and its characteristics can be considered as exemplary for all samples. In other cases, the procedure was analogous. In Figure 1, typical morphology of BM powder is shown. It is illustrated that the grain size of majority particles lay between about 1 to $3 \mu \mathrm{m}$. Contrary to the fact that $\mathrm{KCl}$ acted as anti-sticking ingredient, the smallest particles were loosely aggregated to greater groups, which size was about $10 \mu \mathrm{m}$. 


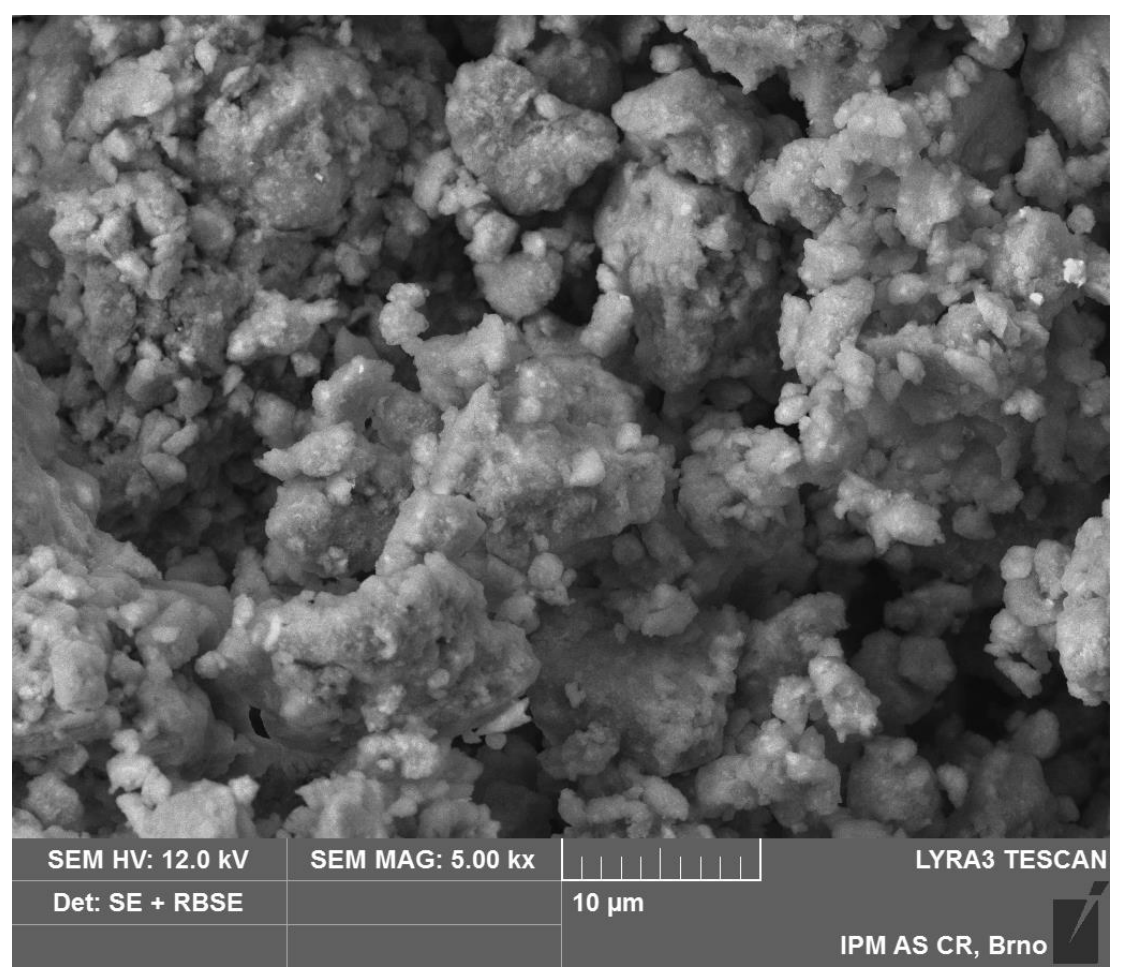

Figure 1 SEM microstructure of BM powder - example: Sample 2

The phase analysis revealed six phases in stabilized samples. Typical XRD pattern is shown in Figure 2.

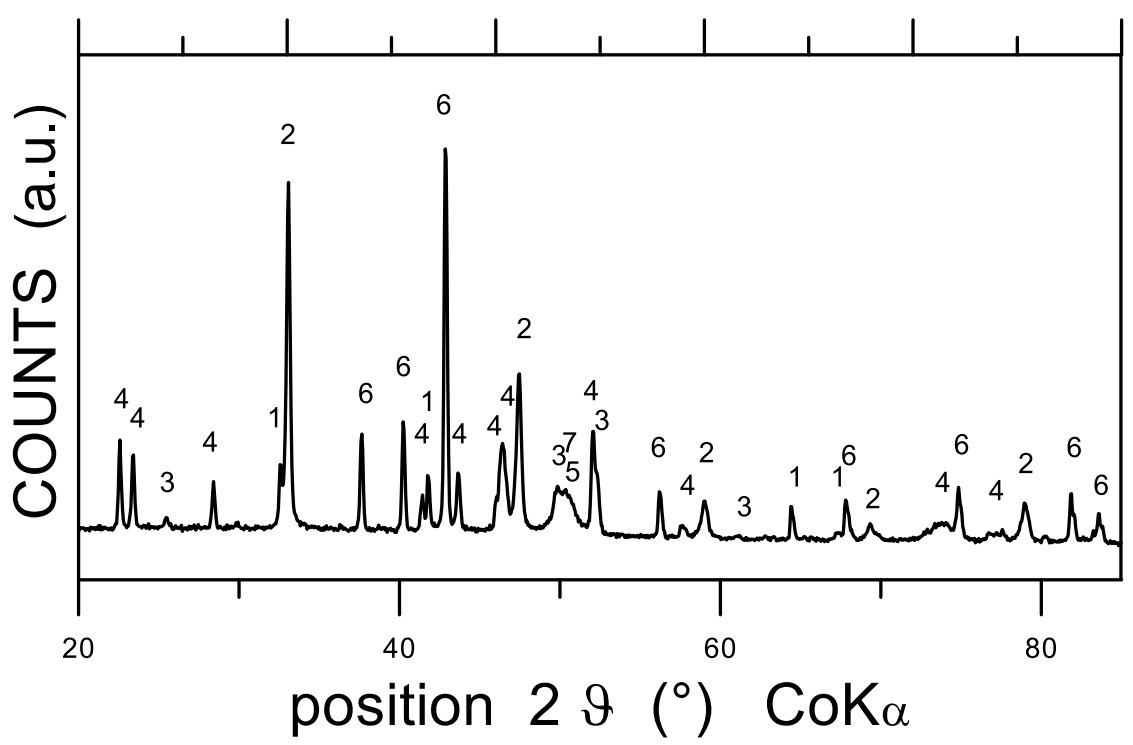

Figure 2 Typical XRD pattern obtained for activated samples: $1-\mathrm{MgH}_{2}, 2-\mathrm{KCl}, 3-\mathrm{MgCu}_{2}, 4-\mathrm{Mg}_{2} \mathrm{Cu}, 5-$

$$
\mathrm{Cu}, 6-\mathrm{Mg}, 7-\mathrm{MgO}
$$

The powder samples were glued to carbon foil and several EDS analyses were done at chosen locations at each sample - see an example in Figure 3.

At individual chosen point, EDS analysis was done - for the spectrum at point 3, see Figure 4 - and the chemical composition was evaluated. Very small concentration of oxygen was present in the form of a low amount of $\mathrm{MgO}$ (see in Figure 2), which was neglected in further evaluation. Results obtained at all points are listed in Table 2. 


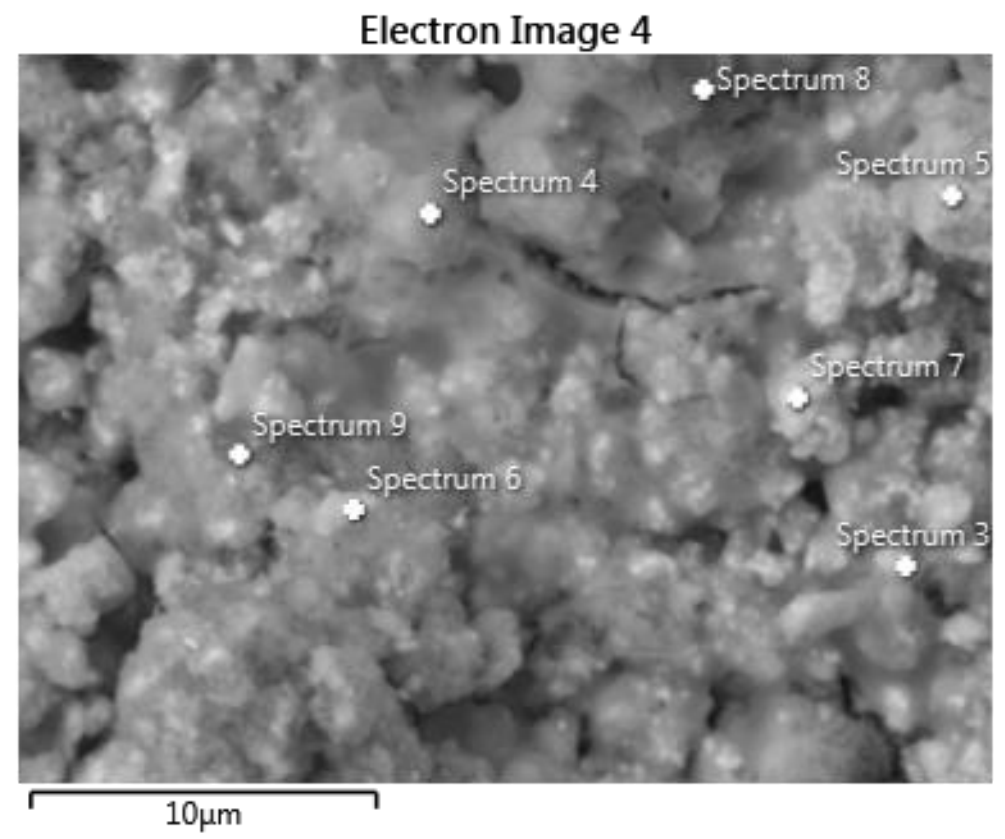

Figure 3 SEM micrograph of BMpowder - example: Choice of analysed locations on Sample 2

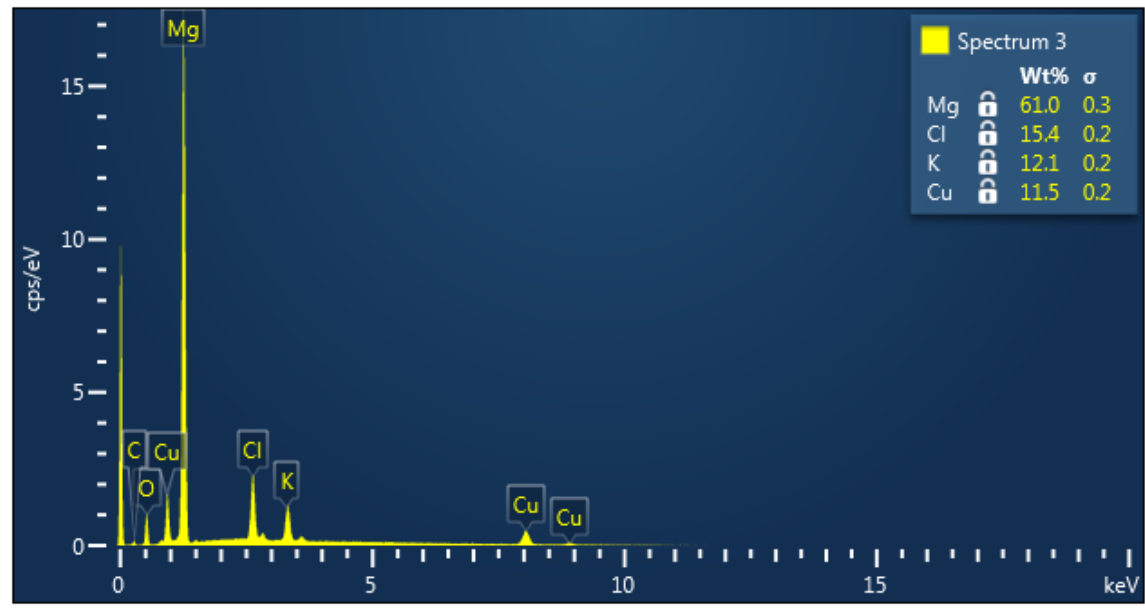

Figure 4 EDS spectrum. Example: Spectrum taken at point 3 on Sample 2

Table 2 Local chemical composition in wt\% measured in points chosen at surface of Sample 2 - see Figure 3.

Values for spectrum 1 represent the average concentration over entire area.

\begin{tabular}{|c|c|c|c|c|c|c|c|c|}
\hline $\begin{array}{c}\text { Spectrum } \\
\text { Label }\end{array}$ & Spectrum 1 & Spectrum 3 & Spectrum 4 & Spectrum 5 & Spectrum 6 & Spectrum 7 & Spectrum 8 & Spectrum 9 \\
\hline $\mathrm{Mg}$ & 51.27 & 60.99 & 66.46 & 31.25 & 46.38 & 47.56 & 37.55 & 63.71 \\
\hline $\mathrm{Cl}$ & 15.34 & 15.41 & 7.41 & 22.49 & 14.09 & 18.12 & 34.52 & 11.84 \\
\hline $\mathrm{K}$ & 18.25 & 12.11 & 9.66 & 37.77 & 16.07 & 20.40 & 24.58 & 6.92 \\
\hline $\mathrm{Cu}$ & 15.14 & 11.49 & 16.48 & 8.50 & 23.45 & 13.91 & 3.36 & 17.53 \\
\hline Total & 100.00 & 100.00 & 100.00 & 100.00 & 100.00 & 100.00 & 100.00 & 100.00 \\
\hline
\end{tabular}

Procedure described above was repeated for all loci and for all three samples. In each location, the ratios of concentrations of $\mathrm{Mg}$ and $\mathrm{Cu}$ and concentrations of $\mathrm{Cl}$ and $\mathrm{K}$ (in atomic \%) were calculated. The former ratio expresses the dominant character of the loci, the latter one scales semiquantitatively the grade of 
(micro)alloying in the respective locus with $\mathrm{K}$ or by $\mathrm{Cl}$. Results, plotted in Figure $\mathbf{5}$ as dependence of $\mathrm{CK}_{\mathrm{K}} / \mathrm{Cl}_{\mathrm{Cl}} \mathrm{vs}$. $\mathrm{CMg} / \mathrm{CCu}$, show the preference of ions and $\mathrm{Cl}$ to enter grains of different base composition.

It is obvious that there is a tendency to a slight enrichment of $\mathrm{Mg}$-rich grains on chlorine from partly decomposed $\mathrm{KCl}$. This can be easily rationalized by values of formation enthalpies of solid crystals, $\Delta H_{f}$, of $\mathrm{KCl}(-435.9 \mathrm{~kJ} / \mathrm{mol}), \mathrm{CuCl}_{2}(-218.9 \mathrm{~kJ} / \mathrm{mol})$ and $\mathrm{MgCl}_{2}(-641.8 \mathrm{~kJ} / \mathrm{mol}$ or $-(644.28 \pm 0.69) \mathrm{kJ} / \mathrm{mol}[9,10])$. Comparing these values of $\Delta \mathrm{H}_{\mathrm{f}}$, it can be easily concluded that $\mathrm{KCl}$ slightly tends to a partial decomposition and chlorine anions enter preferentially $\mathrm{Mg}$-rich regions where they are solved or participate in nucleation of $\mathrm{MgCl}_{2}$ clusters.

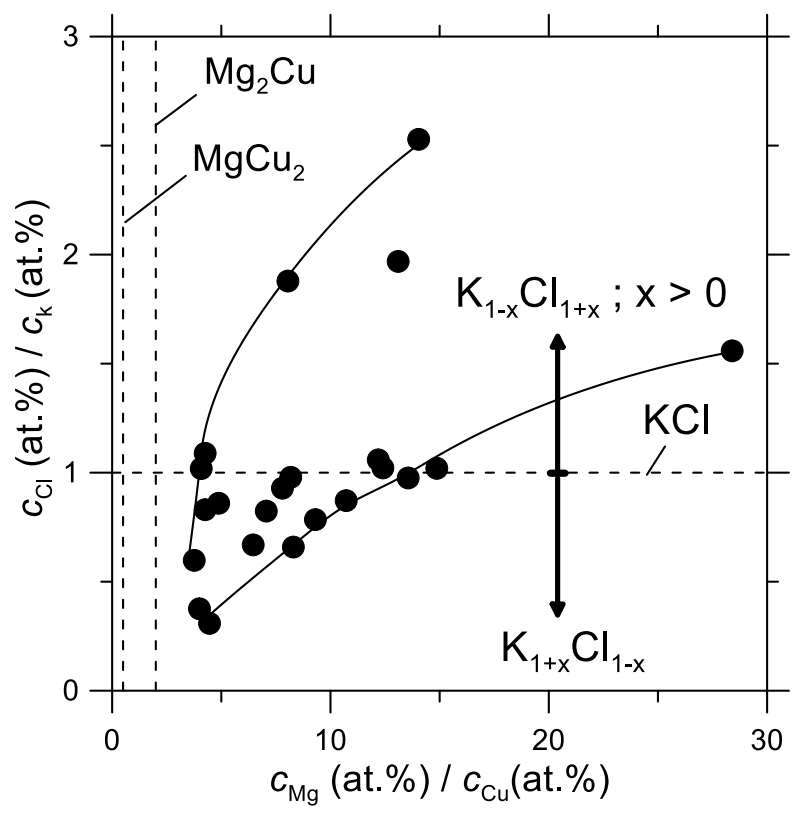

Figure 5 Local chemical composition in randomly chosen loci

\section{CONCLUSION}

The aim of the present paper was to investigate the composition of ball-milled and stabilized $\mathrm{Mg}-\mathrm{Cu}(-\mathrm{KCl})$ alloys that are prospective for hydrogen storage. Special attention was paid to the stability of pristine $\mathrm{KCl}$ and to preference of its dissociation products, $\mathrm{K}$ and $\mathrm{Cl}$, to grains of different chemical composition. It was found that ball-milled and stabilized alloys led to a partial decomposition of $\mathrm{KCl}$ and that $\mathrm{Cl}$ anions preferred incorporation into $\mathrm{Mg}$-rich grains and $\mathrm{K}$ cations enter the $\mathrm{Cu}$-rich component. Since the hydrogen storage in Mg-based alloys is mostly controlled by magnesium hydrides, it can be presumed that $\mathrm{K}^{+}$rather than chlorine anions would control their sorption performance.

\section{ACKNOWLEDGEMENTS}

The present paper was supported by the Institute of Physics of Materials AS CR, CZ-61662 Brno, Czech Republic, program Strategy AV21 and by Central European Institute of Technology and by CEITEC-Institute of Physics of Materials, AS CR Brno, Czech Republic LQ1601.

\section{REFERENCES}

[1] MOLLER, K.T., JENSEN, T.R., AKIBA, LI, H.W. Hydrogen-a sustainable energy carrier. Progress in Nat. Sci.: Materials Int. [online]. 2017, vol. 27, pp. 34-40. Available from: https://doi.org/10.1016/j.pnsc.2016.12.014. 
[2] SAKINTUNA, B., LAMARI-DARKRIM, F., HIRSCHER, M. Metal hydride materials for solid hydrogen storage: A review. Int. J. Hydrogen Energy. [online]. 2007, vol. 32 pp. 1121-1140. Available from: https://doi.org/10.1016/j.ijhydene.2006.11.002.

[3] ZHANG, J., LI, Y., WU, Y., GUO, X., YE, J., YUAN, B., WANG, S., JIANG, L. Recent advances on the thermal destabilization of Mg-based hydrogen storage materials. RSC Advances. [online]. 2019, vol. 9, pp. 408-428. Available from: https://doi.org/ 10.1039/c8ra05596c.

[4] LYU, J., LINDER, A., KUDIIAROV, V. Using ball milling for modification of the hydrogenation/dehydrogenation process in magnesium-based hydrogen storage materials: an overview. Metals. [online]. 2019, vol. 9, pp. 768793. Available from: https://doi.org/10.3390/met9070768.

[5] XU, C., LIN, H.-J., WANG, Y., ZHANG, P., MENG, Y., ZHANG, Y., LIU, Y., ZHANG, J., LI, L., SHI, Q., LI, W., $\mathrm{ZHU}, \mathrm{Y}$., Catalytic effect of in situ formed nano- $\mathrm{Mg}_{2} \mathrm{Ni}$ and $\mathrm{Mg}_{2} \mathrm{Cu}$ on the hydrogen storage properties of $\mathrm{Mg}-\mathrm{Y}$ hydride composites. J. Alloys Compd. [online]. 2019, vol. 782 pp. 242-250. Available from: https://doi.org/10.1016/j.jallcom.2018.12.223.

[6] KARTY, A., GRUNWEIG-GENOSSAR, J., RUDMAN, P. S. Hydriding and dehydriding kinetics $\mathrm{Mg} / \mathrm{Mg}_{2} \mathrm{Cu}$ eutectic alloy: Pressure sweep method. J. Appl. Phys. [online]. 1979, vol. 50, pp. 7200-7209. Available from: https://doi.org/10.1063/1.325832.

[7] CERMAK, J., KRAL, L., ROUPCOVA, P. Improved hydrogen sorption kinetics in Mg modified by chosen catalysts. Int. J. Hydrogen Energy. [online]. 2019, vol. 44, pp. 8315-8324. Available from: https://doi.org/10.1016/j.ijhydene.2019.02.084.

[8] Standard Enthalpy of Formation for Various Compounds [online] @2020. [viewed Nov 18, 2020]. Available from: https://nshs-science.net/chemistry/common/pdf/R-standard enthalpy of formation.pdf.

[9] YI, X., HU, J., SUN, M., MAN, X., ZHANG, Y., LIU, S. Thermal stability and decomposition behaviors of some hydrous transition metal chlorides. J. Thermal Analysis and Calorimetry. [online]. 2019, vol. 138, pp.1633-1640. Available from: https://doi.org/10.1007/s10973-019-08307-4.

[10] SHIN, C., CRISS, C.M. Standard enthalpies of formation of anhydrous and aqueous magnesium chloride at 298.15 K. J. Chem. Thermodynamics. [online]. 1979, vol. 11, pp. 663-666. Available from: https://doi.org/10.1016/0021-9614(79)90032-6. 